\title{
Method of Limiting Shaft Voltages in AC Electric Machines
}

\author{
Sebastian Berhausen $1, *$ (D) and Tomasz Jarek ${ }^{2}$ D \\ 1 Faculty of Electrical Engineering, Silesian University of Technology, 44-100 Gliwice, Poland \\ 2 Łukasiewicz Research Network-Institute of Electrical Drives and Machines KOMEL, \\ 40-203 Katowice, Poland; Tomasz.Jarek@komel.lukasiewicz.gov.pl \\ * Correspondence: Sebastian.Berhausen@polsl.pl
}

check for

updates

Citation: Berhausen, S.; Jarek, T. Method of Limiting Shaft Voltages in AC Electric Machines. Energies 2021, 14, 3326. https://doi.org/10.3390/ en14113326

Academic Editor: Martin Riera-Guasp

Received: 3 May 2021

Accepted: 1 June 2021

Published: 5 June 2021

Publisher's Note: MDPI stays neutral with regard to jurisdictional claims in published maps and institutional affiliations.

Copyright: (C) 2021 by the authors. Licensee MDPI, Basel, Switzerland. This article is an open access article distributed under the terms and conditions of the Creative Commons Attribution (CC BY) license (https:// creativecommons.org/licenses/by/ $4.0 /)$.

\begin{abstract}
The article presents a new method of counteracting shaft voltages and currents in AC electrical machines. It is based on the use of an auxiliary winding located in the stator of the machine. The design of a test stand adapted to the measurement of shaft voltages of the machine, based on the prototype of a synchronous machine with permanent magnets, has been presented. The model was used to conduct a number of laboratory tests aimed at confirming the functionality of the auxiliary winding in various operating states of the machine (including no-load and load condition during generator operation). The article focuses on demonstrating the beneficial effect of the auxiliary winding on the level of induced shaft voltages in an electric machine. In order to confirm the close dependence of the circular flux in the stator yoke on the shaft voltage, shaft voltage measurement results for various cases of external power supply of auxiliary winding forcing a circular flux are presented. Regardless of the laboratory tests, a simulation model of a synchronous machine with permanent magnets, on which calculations were carried out to analyze the work of the auxiliary winding located in the stator yoke, was developed. The article is supplemented by a review of damage to electrical machines with a detailed description of bearing defects, as well as a brief de-scription of issues related to the mechanism of generating shaft voltages and currents in electrical machines and methods of counteracting them.
\end{abstract}

Keywords: bearing currents; shaft voltages; electrical machine; bearings

\section{Introduction}

Electric machines operating based on the principle of electromagnetic induction constitute the widest class of electromechanical transducers and currently occupy a leading position among all technical devices.

The development of electrical machines dates back to the 19th century. Owing to the inventions of Nicola Tesla, Galileo Ferraris and, in particular, Mikhail Dolivo-Dobrovolski, the first designs of 3-phase electric machines were created at the end of the 19th century [1]. At the turn of the 19th and 20th centuries, the general concept and construction of alternating current machines was formed. The subsequent years provided a large number of scientific and technical studies in the field of theory, design optimization or operational properties etc. of electrical machines [2-4]. With the development of industry and the use of ever new construction materials, electrical machines found more and more applications in, among others, pump and fan drives, transport systems and traction. For over 10 years, there has been a growing interest in electric motors used to drive electric [5] and hybrid vehicles [6]. It is estimated that currently electric machines account for approximately $46 \%$ of electricity consumption in the world [7].

The experience gathered over the decades of operation of electrical machines shows that their failure rate is systematically decreasing. This is due to, among others, the use of: better insulation, better diagnostic methods [8] and improving the quality of service during operation. It should be noted that the algorithms and control systems also have a significant impact on the operational properties and reliability of the machine [9]. Despite 
this, the problem related to the failure rate of electrical machines still requires attention, as evidenced by numerous works carried out in many research and development centers [10]. The most common failures of electrical machines include: [11]:

- Degradation of the main and turn-to-turn insulation of the stator winding.

- Rotor failures (e.g., broken rotor bars in an induction machine, demagnetization of rotor permanent magnets).

- Bearing damages.

- Shaft breakage or damage to the couplings.

The percentage share of the above types of damage on the example of induction machines is shown in Figure 1 [12].

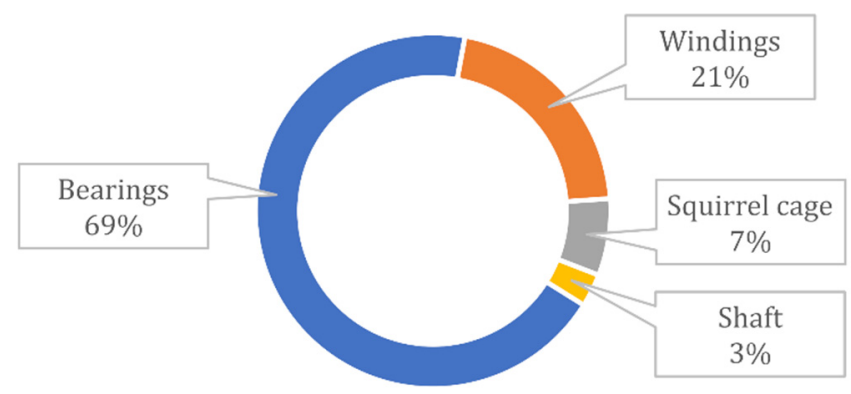

Figure 1. Percentage distribution of failure occurrence in induction machines.

The above pie diagram shows that the vast majority of failures in electrical machines relate to bearings. In view of the above, the issue of their damage is a timely issue.

Bearings are machine structural elements that enable rotor rotation with low mechanical losses. They are subjected to an intensive wear process. Even though the cost of the bearings is low, compared to the cost of the electric machine, their damage generates additional economic losses due to the shutdown of the machine for overhaul. Bearing failures occur in the ball, roller and plain bearings and may concern: external and internal raceways, as well as rolling elements and a cage. Additionally, due to the flowing bearing current, the journals of the connected shafts are often damaged [13].

It should be noticed that in the available literature there are solutions for bearingless electrical machine constructions, in which there are no standard wear problems (friction, lubrication, bearing currents, etc.). However, such a solution requires the use of advanced control algorithms $[14,15]$.

\subsection{Causes of Bearing Failures}

The main causes of damage to rolling elements, raceways of bearings and journals of connected shafts include thermal and mechanical damages as well as damages due to flow of bearing currents. The tendency to suffer thermal and mechanical damage results, among others, from [11]:

- Small play in bearings.

- Insufficient lubrication or incorrectly selected lubricant.

- Vibrations resulting from rotor unbalance, excessive play, journal eccentricity, etc.

- Asymmetry in the air gap of the machine contributing to uneven magnetic pull or incorrect centering of the motor and driven machine.

Each of the above sources of bearing damage is characterized by different marks on the inner and outer raceways and on the rolling elements. The nature of these failures and the description of their causes have been widely described both in the materials provided by the manufacturers of rolling bearings [16-19] as well as in publications [20,21]. The effect of using a bearing with an unsatisfactory technical condition may be flaking, scratches, abrasions and cracks on the surface of the raceway and rolling elements. A detailed inspection of these surfaces after dismantling the bearing makes it possible to analyze the potential causes of damage. Particular attention should be paid to the operating path of the 
bearing (ball and roller). On its basis it is possible to determine the bearing load conditions resulting from assembly and operation. Discoloration and corrosion effects can also be a source of knowledge about the operating parameters of the bearing.

Other sources of bearing failures are the currents that flow through them. These currents significantly reduce the failure-free operation of the machine. Particular attention should be paid to this phenomenon in drive systems, which require high operational reliability. Visual inspection of the rolling bearing elements confirms that in many cases there are visible traces of bearing current flow (Figure 2). Damage resulting from the flowing bearing current most often takes the form of pits or burns on the surfaces of the bearing raceways and rolling elements [20]. They can assume characteristic shapes in a straight, zigzag line and also accumulate pointwise forming craters. The intensity of this damage depends on the density of the flowing current and the duration of its operation. It should be added that bearing currents can flow not only through the bearings of the electrical machine, but also through conductive couplings connecting two machines, contributing to the damage of the shaft journals. This is related to the change in the bearing current flow path, which is conditioned by the architecture of the electric connections of the drive unit (power cables, grounding, equipotential bonding, etc.). The current can flow through the shaft and the conductive coupling to the machine and close through its bearing to ground back to the machine and flow through the bearing back to the shaft. As a result of this current flow, traces of electro-corrosion may appear on the shaft and the coupling, leading to their damage. Figure 2c shows examples of electro-corrosion marks of the electric machine shaft journal, which appear in the form of dark marks on the shaft surface.

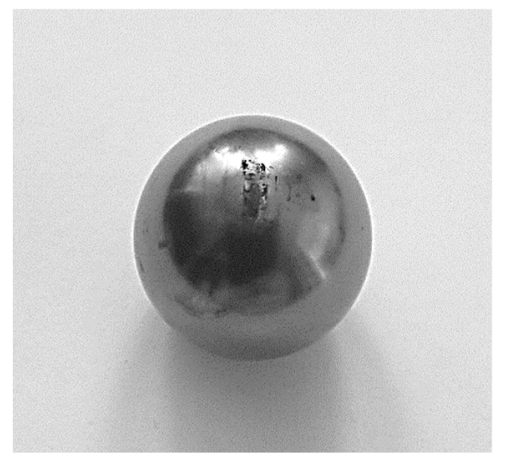

(a)

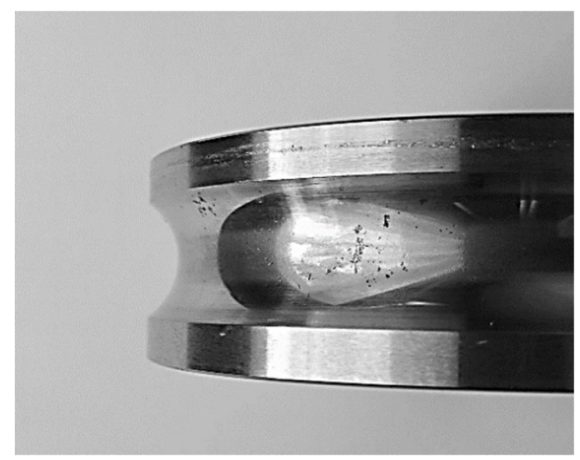

(b)

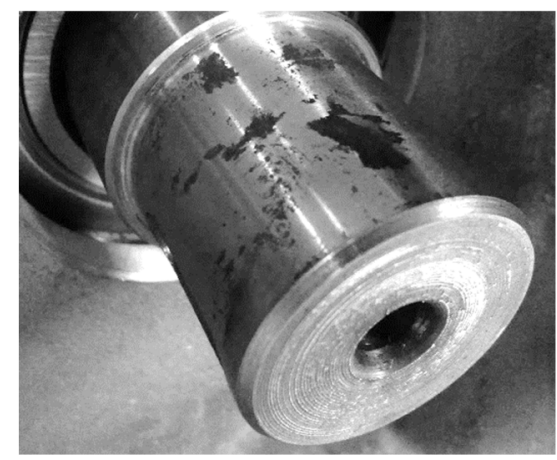

(c)

Figure 2. Damage to the electric machine caused by the flow of shaft current: bearing ball (a) inner bearing race (b) and shaft journal (c).

The flow of the bearing current causes damage that entails serious threats to the proper operation of the drive system, contributing to the damage of the bearings, shafts and couplings, often leading to a failure that requires a new stator and rotor winding.

The phenomenon of generating shaft voltages and currents in rotating electric machines was observed at the beginning of the 20th century. One of the first works that addressed the issue of this phenomenon dates back to 1923 [22]. It showed-similarly as the subsequent publications [23-25], that one of the causes of induction of the shaft voltage is the asymmetry of the magnetic field in the electromagnetic circuit of the machine. Such asymmetry may stem from many factors:

- $\quad$ Rotor eccentricity (circumferential irregularity of the air gap or arc bending of the shaft).

- Asymmetry caused by a short circuit of the stator core or rotor sheets.

- Non-uniformly magnetized permanent magnets placed in the electromagnetic circuit.

- Anisotropy of the sheets forming an electromagnetic circuit.

- Turn-to-turn short-circuits in stator or rotor windings.

- Cracks in the bars or end rings of the rotor cage. 
- Differences in the magnetic conductivity of individual segments of the electromagnetic circuit.

- Unbalanced feeding of the machine stator windings.

- Asymmetrical arrangement of ventilation ducts in the electromagnetic circuit.

Some of the above-mentioned factors may manifest themselves already at the stage of machine production, as a consequence of the tolerance chain and production inaccuracies and material properties, as well as during operation, e.g., in the case of rotor damage.

An example of the asymmetry of the magnetic flux in a machine is shown in Figure 3. The cross-section of a 4-pole synchronous machine with permanent magnets placed on the rotor presents the flow path of the main flux of the machine $\Phi_{\mathrm{m}}$, which closes through the stator yoke, stator teeth, air gap, magnets placed on the rotor and the rotor yoke. In the case of perfect symmetry of the machine's electromagnetic circuit, each of the fluxes enclosing one pole of the stator yoke has the same distribution of the magnetic field force lines. If, for any of the above-mentioned reasons, the electromagnetic field in the magnetic circuit is asymmetrical, then the resultant circular flux $\Phi_{\text {ring }}$ will flow in the stator yoke [26]. This flux does not take part in the torque conversion, but it is the source of the electromotive force at the ends of the machine shaft, further on referred to as the shaft voltage.

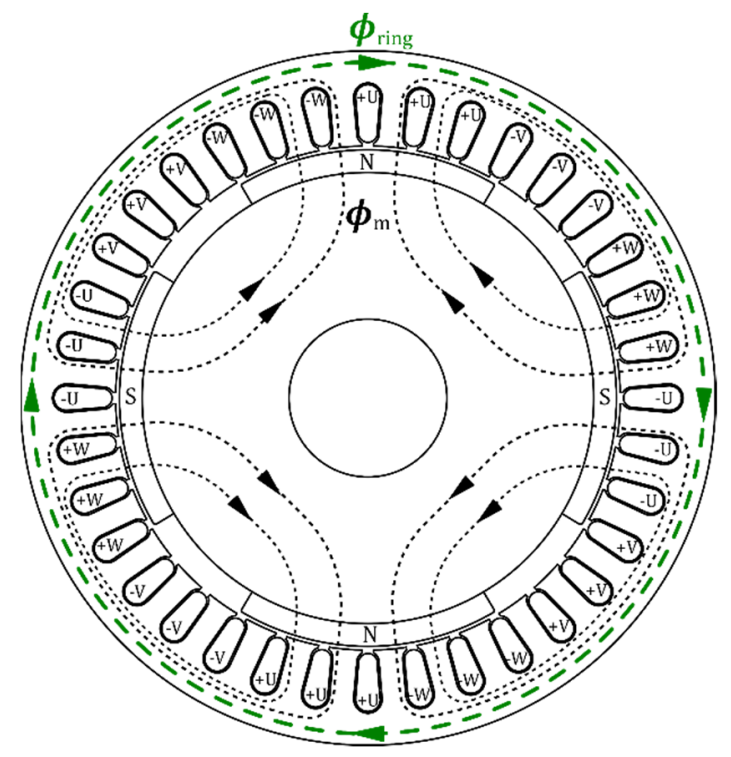

Figure 3. A circular flux $\Phi_{\text {ring }}$ in the stator yoke of a permanent magnet synchronous machine.

Due to the induced potential difference, a shaft current can flow between the machine shaft ends. The shaft voltage and an example of the shaft current flow path are presented in the simplified section of the machine in Figure 4. The shaft current may close through the shaft, bearings, endshields and frame. The phenomenon of shaft currents occurs in practically every type of an electric machine, also in synchronous machines excited by permanent magnets [27]. They are most often found in high-power electrical machines, especially in dynamic states, e.g., during heavy start-ups [28]. 


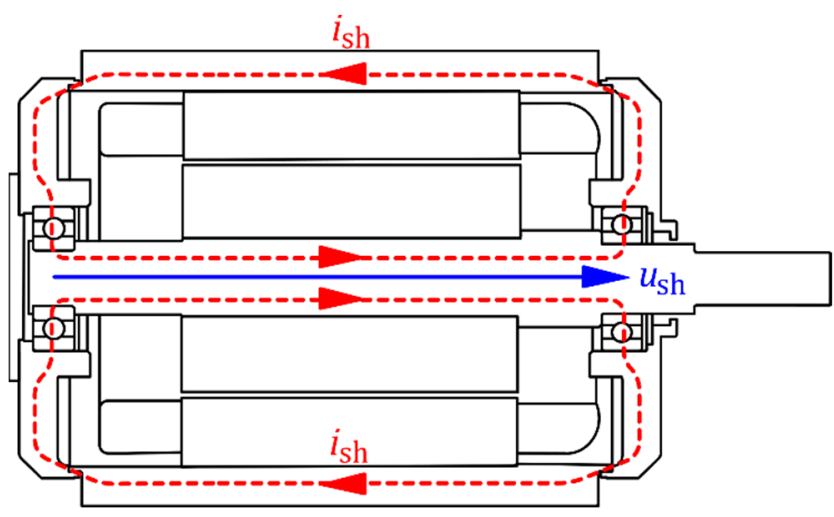

Figure 4. Shaft voltage $u_{\mathrm{sh}}$ and shaft current $i_{\mathrm{sh}}$ on a cross-section of an electric machine.

\subsection{Selected Methods of Counteracting Bearing Currents}

In order to protect the rolling bearings against the destructive effects of the bearing currents, measures should be taken to prevent the flow of the bearing current or limit the shaft voltage. Over the years, a number of solutions have been developed to reduce the phenomenon of the shaft voltages and the bearing currents. The development of technology, diagnostic methods as well as the experience gained in practice have contributed to the development of various strategies to counteract these phenomena. These, in turn, can be categorized into the following:

- Elimination or limitation of the source of the shaft voltage.

- Hindering the flow of the bearing current by increasing the impedance of the path through which the current can flow.

- Controlled flow of the bearing current, limiting the risk of damage to the components of the drive system, in particular the bearings.

In the case of electrical machines powered from AC mains, the key aspect that affects the level of the shaft voltage is the symmetry of the electromagnetic circuit [29]. Therefore, already at the design stage, it is crucial to evenly distribute the electromagnetic circuit of the stator and rotor windings, ventilation ducts and other elements that may cause flux asymmetry. In the case of high-power machines, an important aspect is to ensure even segmentation of the sheets [22]. Despite this, imperfections of technological processes, the tolerance chain as well as the asymmetries of the electromagnetic circuit that occurred during operation (e.g., damage to the asynchronous rotor cage, thermal demagnetization of the rotor permanent magnets, turn short-circuits in the stator windings, etc.) may cause the flow of shaft currents.

One of the most frequently used methods of limiting bearing currents in electrical machines is to increase the impedance of possible paths of their flow through the use of bearing insulation. The dielectric properties of the bearing are achieved, among others, owing to the use of rolling elements and raceways made of ceramic materials [16] or through the use of thermally cured aluminum oxide coatings $\left(\mathrm{Al}_{2} \mathrm{O}_{3}\right)$ [30]. It is worth noting that the path of the shaft current flow does not have to be limited exclusively to one variant shown in Figure 5. The complexity of the structure, especially in the case of dedicated, specialized drive systems, often coupled with mechanical transmissions, characterized by many bearing assemblies, leads to multi-variant paths through which the shaft current may close. Alternative solutions include the ones aimed at shunting the bearing current, thus increasing the durability and reliability of the bearing.

If the shaft voltage source is the shaft residual magnetism $[25,31]$ the shaft should be demagnetized. One of the methods would be to use a dedicated coil wound around the shaft. In this case, the flow of alternating current of smaller and smaller amplitude demagnetizes the shaft in accordance with gradually decreasing hysteresis loop. As a result, the residual magnetism is reduced. 


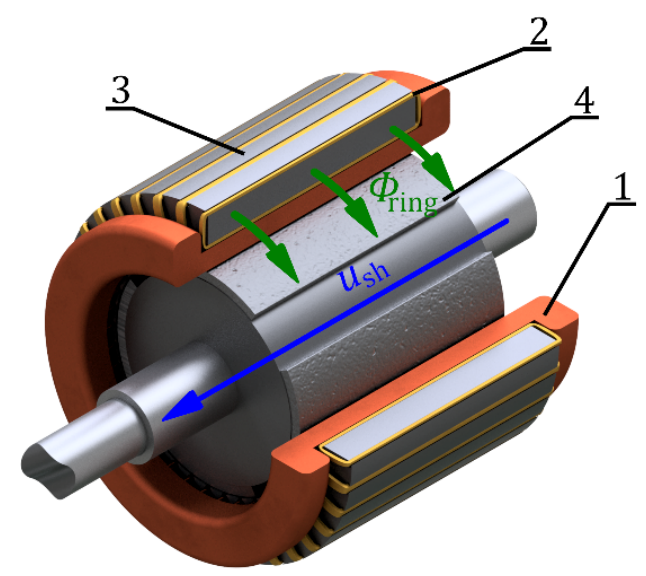

Figure 5. Electromagnetic circuit of a permanent magnet synchronous machine with an auxiliary winding wound around the yoke: 1 . main winding, 2. auxiliary winding, 3 . stator core, 4 . permanent magnet rotor.

\section{The Idea of an Auxiliary Winding in an Electric Machine}

The authors of the article suggest using an auxiliary toroidal winding to eliminate shaft currents in an AC electric machine. The method of minimizing bearing currents presented in the article is new, and its undoubted advantage, unlike the solutions used so far, is the lack of the need to use additional peripheral devices, because the cause of shaft voltage generation is eliminated by the machine structure.

The auxiliary winding is wound around the stator yoke-the sides of the individual winding coils lie at the bottom of the stator slots, the other sides in small depressions on the outer surface of the stator core. This winding is illustrated in Figure 5.

The individual winding coils of the auxiliary winding are connected in a series with one another (keeping the same winding direction) - the layout of the winding connections is shown in Figure 6. A characteristic feature is the equal number of turns in all coils of the auxiliary winding. The number of auxiliary winding coils is equal to the number of slots in the stator core. In each coil of the auxiliary winding, a voltage is induced due to the change in time of the flux associated with it (passing through the yoke in the plane of the coil). According to the Equation (1), the voltage at the terminals of the entire auxiliary winding is equal to the sum of the instantaneous voltages induced in individual coils.

$$
u_{\mathrm{aux}}=\sum_{i=0}^{q} u_{\mathrm{aux}(q)}
$$

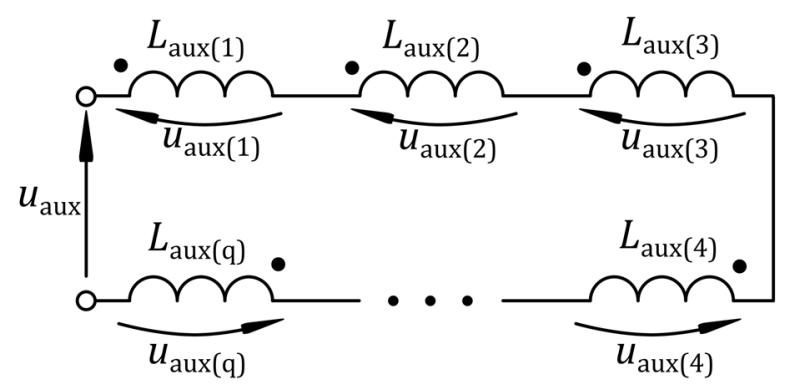

Figure 6. Diagram of the auxiliary winding connection: $L_{\mathrm{aux}(1)}, L_{\mathrm{aux}(2)}, \ldots, L_{\mathrm{aux}(q)}$-self-inductance of $q$-th auxiliary winding coil, $u_{\mathrm{aux}(q)}$-voltage induced in the nth coil of the auxiliary winding, $u_{\text {aux }}$ - auxiliary winding voltage, $q-$ number of auxiliary winding coils, it is equal to number of stator slots.

In the auxiliary winding constructed in such a way, in the case of symmetrical distribution of the magnetic flux in the electromagnetic circuit of the machine, the sum of the 
instantaneous voltages induced in individual coils at the terminals of this winding will be equal to zero (1). The star of the voltages of the auxiliary winding coils is shown in Figure 7. A 4-pole electric machine with 36 slots of the stator is used as an example. Due to the number of pole pairs $(p=2)$, the diagram has been limited to 18 voltage vectors-for the remaining slots (19-36) star of the voltages has an identical shape. In the case of a symmetrical distribution of the main flux in the electromagnetic circuit of the machine, the induced voltages in all coils are characterized by the same amplitude and phase shift depending on the slot pitch and the number of pole pairs. However, in the case of asymmetry of the magnetic field distribution, the voltage at the terminals of the auxiliary winding will be non-zero. After the auxiliary winding terminals are short-circuited, a current will flow in the closed circuit of this winding, which will generate a magnetic flux in the stator yoke directed opposite to the circular flux $\Phi_{\text {ring. }}$. In this way, the circular flux will be suppressed, limiting the phenomenon of shaft voltage/current generation. The idea of using such a winding was also described in the authors' earlier publication [32].

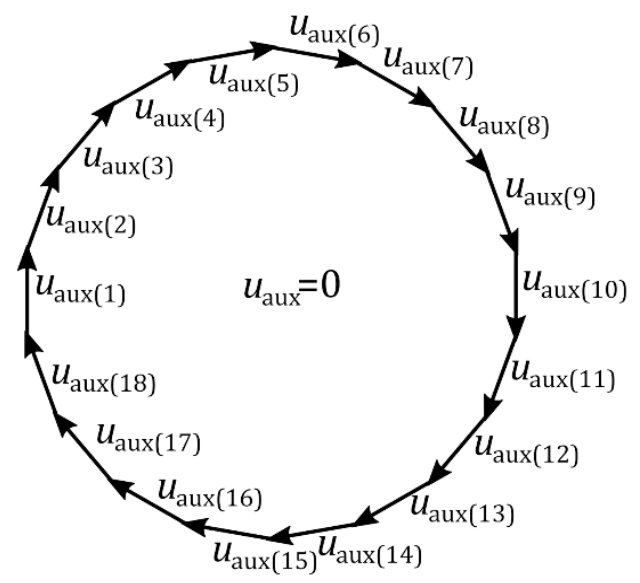

Figure 7. The star of the voltages of an individual coil of the auxiliary winding in the case of zero circular flux in the stator yoke for a 4-pole machine $(2 p=4)$ with the number of stator slots equal to $Q_{\mathrm{S}}=36$.

\section{Machine Simulation Model and Calculation Results}

As part of the work, a two-dimensional field-circuit simulation model of a synchronous generator with permanent magnets with an auxiliary winding was developed. This model was developed in the Maxwell environment included in the Ansys software. The geometric dimensions, material properties and other design parameters of the model were determined on the basis of the documentation of the prototype of the machine research model presented in Chapter 4. The field part of the model is shown in Figure 8a, while the circuit part is shown in Figure $8 b$. 


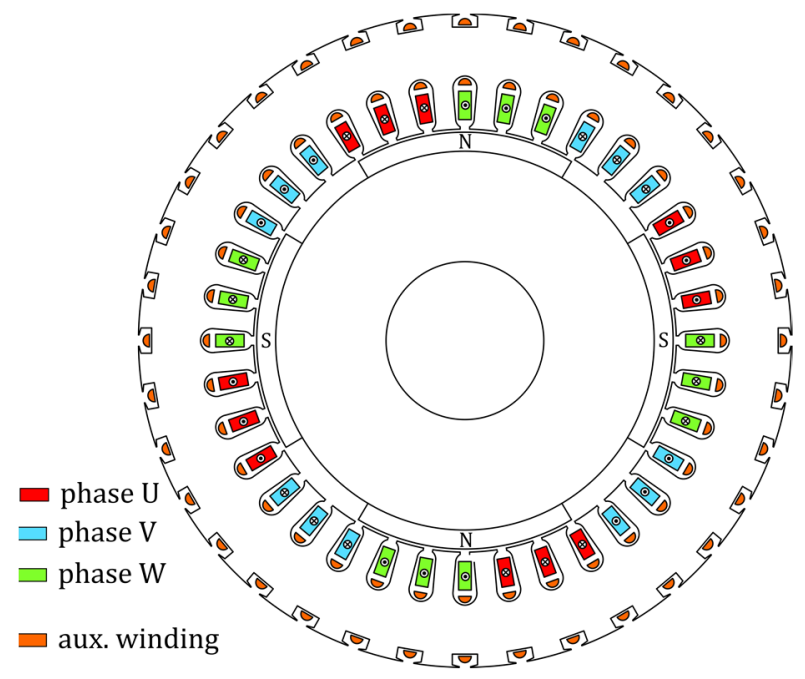

(a)

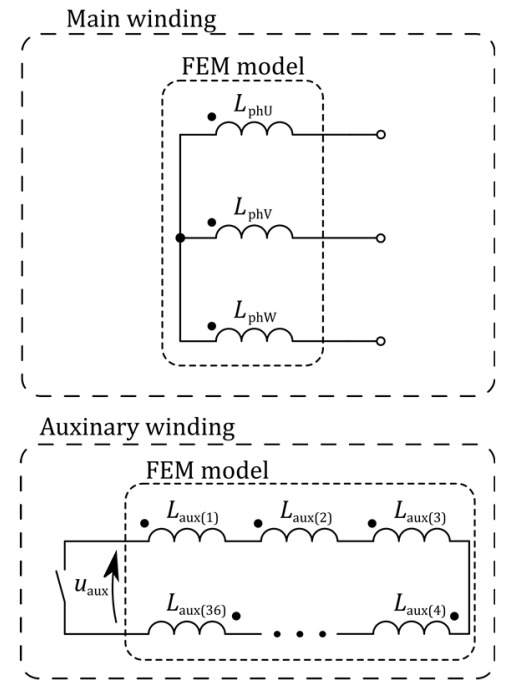

(b)

Figure 8. Simulation model of a permanent magnet synchronous machine with an auxiliary winding: field part (a) and circuit part (b).

The arrangement of the auxiliary winding coils along the entire stator yoke and the performed analysis of the asymmetry of the electromagnetic circuit in the form of an uneven air gap result in the necessity to apply the full field model. When creating the finite element mesh, special attention was paid to its density in the air gap and in the stator core. The finite element mesh, shown in Figure 9, consists of 48,900 nodes. The simulation step was $\Delta t=1 \mathrm{~ms}$.

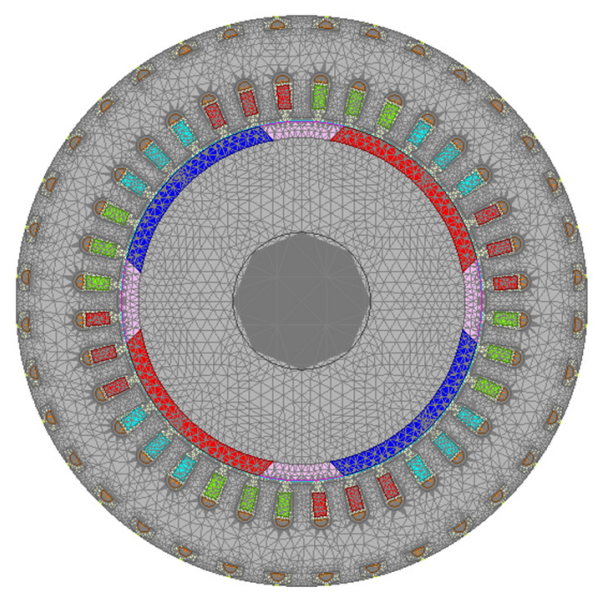

Figure 9. Finite element mesh of the developed model.

Based on the simulation of the generator's operation with the main winding terminals open, the induced voltage waveforms in the individual coils of the auxiliary winding were obtained, as shown in Figure 10. Similarly, as in the case of the voltage star shown in Figure 7, the obtained waveforms were also limited to 18 coils. In the case of perfect symmetry of the machine's electromagnetic circuit, the induced voltages in all coils have an identical shape with a phase shift resulting from the slot pitch and the number of pole pairs. In this case, there is no potential difference at the terminals of the auxiliary winding that consists of 36 coils connected in series, as shown in Figure 11. 


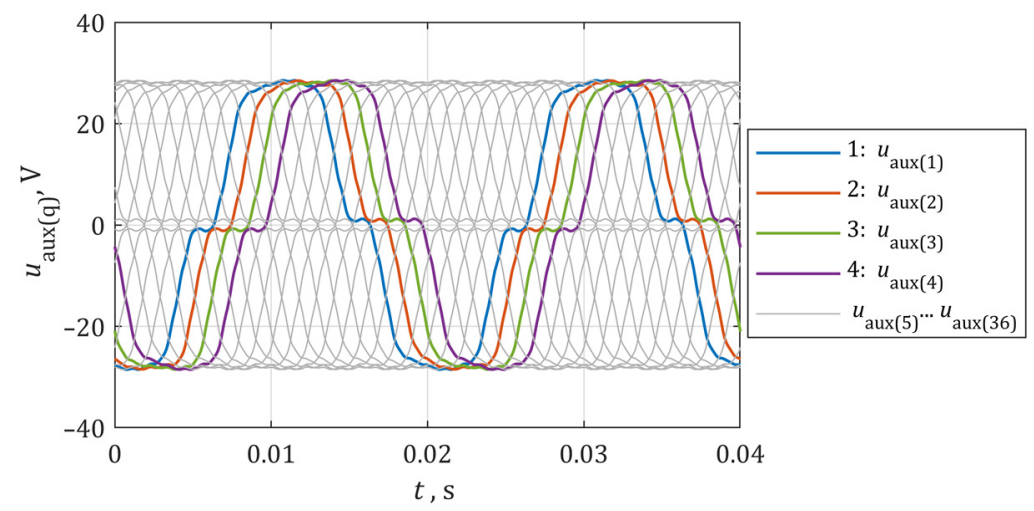

Figure 10. Waveforms of induced voltages in individual coils of the open auxiliary winding, calculated using FEM in the case of the ideal symmetry of the electromagnetic circuit of the machine operating at no-load conditions at the speed $n=1500 \mathrm{rpm}$.

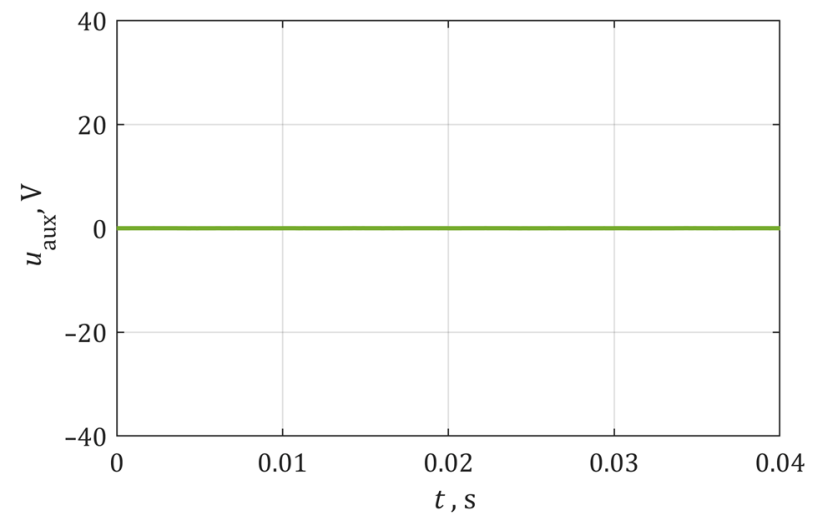

Figure 11. Waveform of the voltage induced on the terminals of the open auxiliary winding calculated using FEM in the case of the ideal symmetry of the electromagnetic circuit of the machine operating at no-load condition at the speed $n=1500 \mathrm{rpm}$.

The second analyzed case is the introduction of air gap asymmetry in the simulation model. The simulations were carried out for static eccentricity based on shifting the stator axis in relation to the rotor rotation axis. Figure 12 shows the static eccentricity adopted for the tests. The shift was half the thickness of the air gap, which corresponds to the eccentricity factor:

$$
\varepsilon_{\%}=\frac{\varepsilon}{d} 100=50 \%
$$

where: $d$-average thickness of the air gap between the stator and the magnet glued onto the rotor surface.

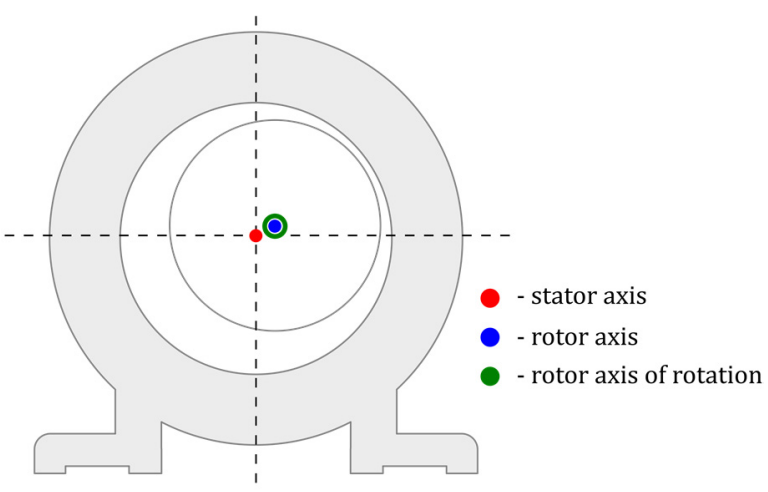

Figure 12. Static eccentricity of the machine. 
Figure 13 shows the results of calculations of the voltage waveforms induced in individual coils of the auxiliary winding of the machine operating at no-load condition at the speed $n=1500 \mathrm{rpm}$, and Figure 14 shows the voltage being the sum of the instantaneous values of induced voltages and its harmonic spectrum.

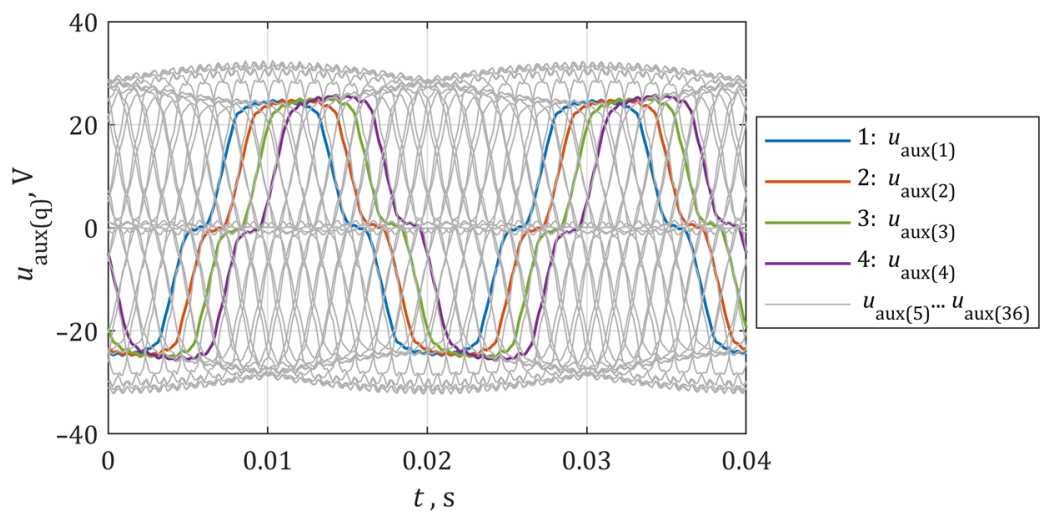

Figure 13. Waveforms of induced voltages in individual coils of an open auxiliary winding calculated using FEM in the case of static eccentricity of the machine working at no-load conditions at the rotational speed $n=1500 \mathrm{rpm}$.

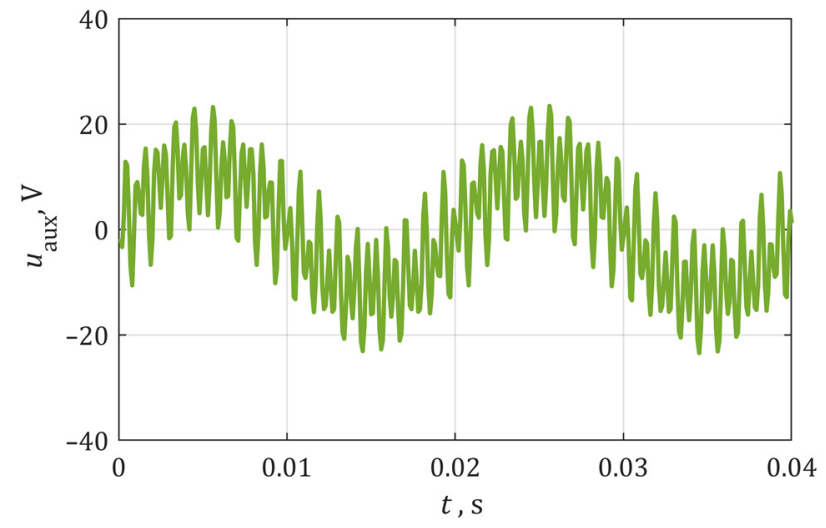

(a)

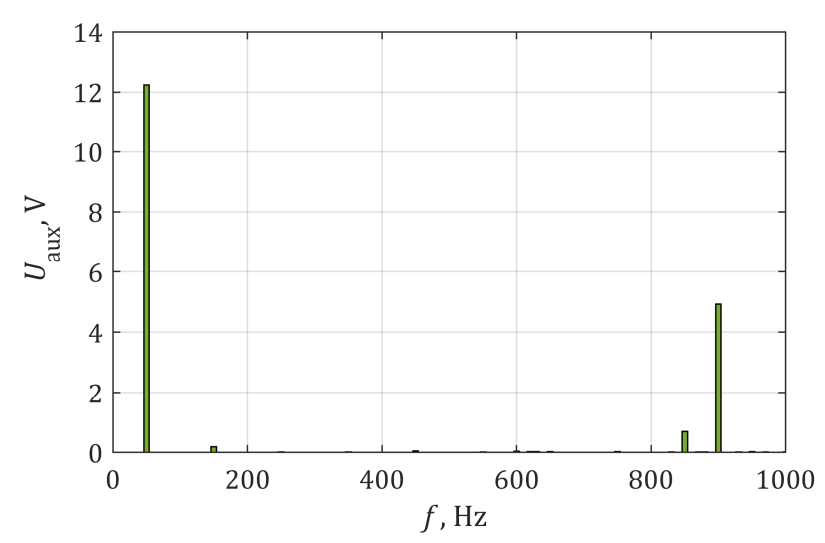

(b)

Figure 14. The waveform of the voltage induced on the open auxiliary winding terminals (a) and its harmonic spectrum (b) calculated using FEM in the case of static eccentricity of the machine operating at no-load conditions at the rotational speed $n=1500 \mathrm{rpm}$.

Based on the above calculation results, it can be concluded that the asymmetry of the air gap is the cause of differences in the induced voltages in individual coils of the auxiliary winding, which leads to the occurrence of the voltage at the terminals of the auxiliary winding. The voltages with the highest amplitude are induced in the coils where the air gap is minimal, while in the area where the greatest thickness of the gap occurs, voltages with the smallest amplitude are observed. The harmonic analysis of the voltage induced on the auxiliary winding terminals shows that the dominant value is the harmonic with the frequency $f=50 \mathrm{~Hz}$. Another dominant harmonic is the slot harmonic with the frequency $f=900 \mathrm{~Hz}$.

\section{Research Model}

In order to confirm the functionality of the auxiliary winding, a test stand was built at the Institute of Electric Drives and Machines KOMEL. The main element of this stand is a prototype of a synchronous machine with permanent magnets. The basic rating and design data are included in Table 1. A fragment of the stator with a visible auxiliary winding is 
shown in Figure 15a, and the rotor is presented in Figure 15b. The sides of the individual auxiliary winding coils are located at the bottom of the main slots and in the slots on the outer surface of the stator core. All coils of the winding were connected in a series aiding arrangement, and the ends of the winding were placed in the terminal box. In the remaining part of the stator slots a three-phase one-layer main winding into a star arrangement is placed.

Table 1. Basic rating and design data of the prototype of the tested machine.

\begin{tabular}{ccc}
\hline Parameter & Symbol & Value \\
\hline Shaft height & $H$ & $132 \mathrm{~mm}$ \\
Number of poles & $2 p$ & 4 \\
Number of stator phases & $m$ & 3 \\
Rated power & $S_{\mathrm{N}}$ & $7.2 \mathrm{kV} \mathrm{A}$ \\
Rated voltage & $U_{\mathrm{N}}$ & $3 \times 400 \mathrm{~V}$ \\
Rated frequency & $f_{\mathrm{N}}$ & $50 \mathrm{~Hz}$ \\
Number of stator slots & $Q_{\mathrm{S}}$ & 36 \\
\hline
\end{tabular}

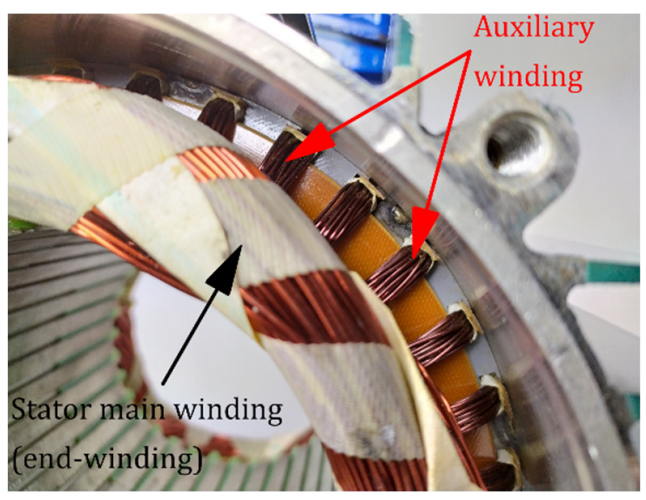

(a)

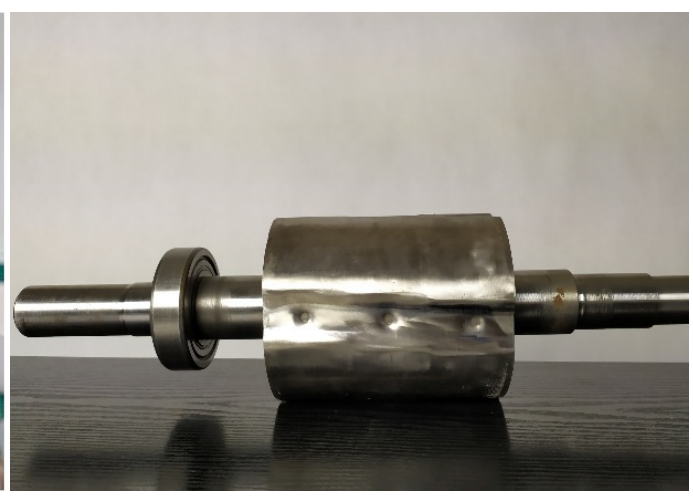

(b)

Figure 15. View of the research model: fragment of the stator with the auxiliary winding marked (a) rotor with permanent magnets $(\mathbf{b})$.

Neodymium magnets forming 4 magnetic poles were glued to the outer surface of the rotor. There are 3 magnets for each pole, angularly shifted to each other, creating a skew corresponding to one stator slot pitch. The magnets were secured against detachment due to centrifugal force.

The structure of the test stand is shown in Figure 16. The research model-a synchronous machine with permanent magnets was placed on the assembly frame and coupled with a DC drive machine through a coupling with an insulating polyurethane spider. In this way, mechanical coupling of the machines ensures, apart from galvanic isolation, minimization of vibrations and compensation of misalignment of the connected journals. The non-drive bearing end-shield, the ventilator and its cover have been removed. The bearing assembly was created using a self-aligning bearing in the housing. This bearing was isolated from the rest of the test stand using a dielectric base. This solution made it possible to measure the actual shaft voltage, not shunted by the bearing plates and the frame. This modification is a significant difference to the research model presented in the earlier article [32]. 


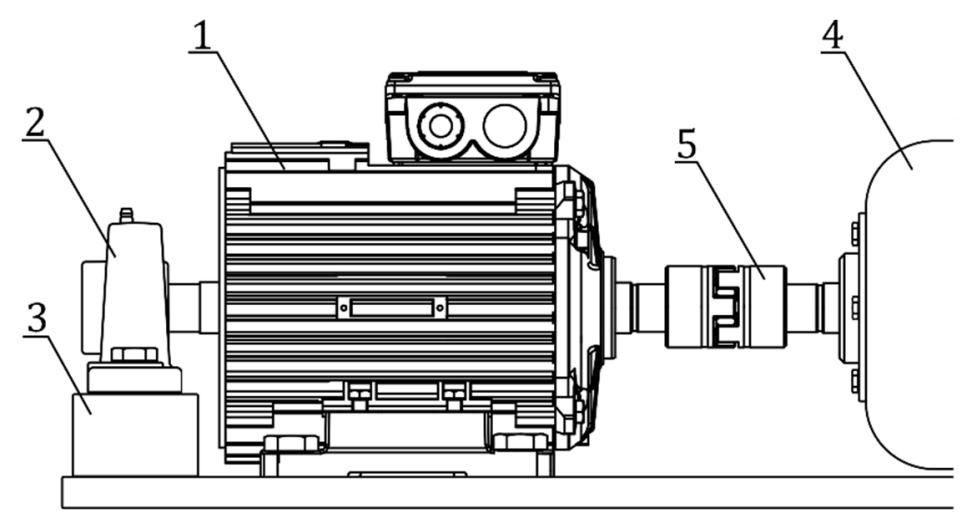

Figure 16. Construction of the test stand: 1. permanent magnet synchronous generator (research object), 2. pillow block ball bearing unit, 3. electrical insulating base, 4 . auxiliary machine, 5 . torsionally flexible jaw coupling with polyurethane spider.

The connection diagram of the stator main and auxiliary windings is presented in Figure 17. The three-phase star-connected stator winding (U-V-W) is connected to a regulated $\mathrm{AC}$ voltage source $\left(u_{\mathrm{L} 1}, u_{\mathrm{L} 2}, u_{\mathrm{L} 3}\right)$ at mains frequency via a three-pole contactor (K1). In turn, the auxiliary winding (X1-X2) is connected to the double-pole switch (K2) which allows it to be short-circuited. A high-class oscilloscope (Tektronix MDO 3034) and probes: voltage (Tektronix P5205) and current (Tektronix: P5205 and TCP0150) were used for the measurements. The probe settings were detected automatically by the oscilloscope.
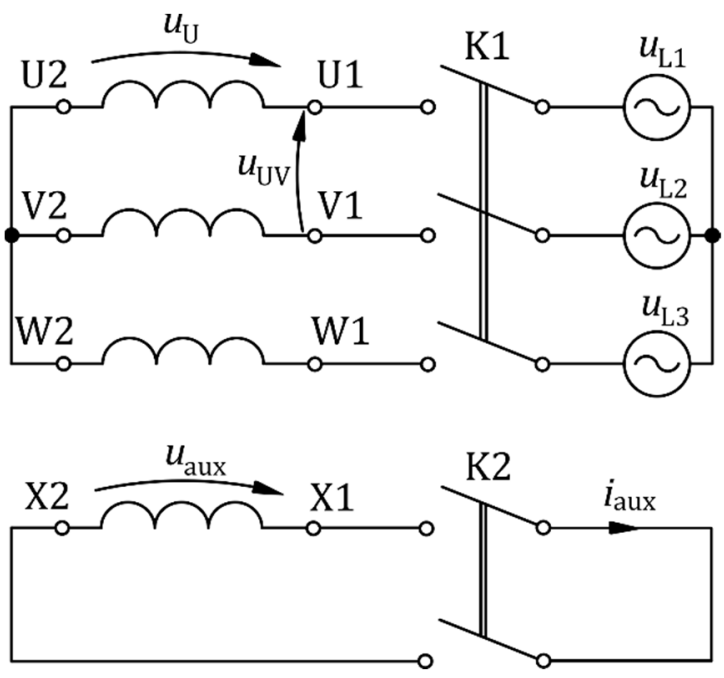

Figure 17. Connection diagram of the stator main winding and auxiliary winding.

\section{Research on a Laboratory Model}

The research and measurement program was designed in such a way that, using the available measuring equipment and other auxiliary devices, it was possible to draw conclusions about the usefulness of the auxiliary winding and its influence on the levels of shaft voltages induced along the shaft of the machine.

At the beginning, tests were carried out to determine the effect of the circular flux flowing in the stator yoke on the shaft voltage of the machine. To that end, the auxiliary winding was supplied from a regulated AC voltage source $u_{\text {ext }}$ with a frequency of $f=50 \mathrm{~Hz}$, as shown in Figure 18. The first variant of the measurements concerned the case of a stationary rotor and an open main winding. The voltage $u_{\text {aux }}$ and current $i_{\text {aux }}$ of auxiliary winding and the voltage between the journals of the shaft $u_{\text {sh }}$ were acquired. The current waveforms of the auxiliary winding $i_{\text {aux }}$ and the shaft voltage $u_{\text {sh }}$ are shown in Figure 19. The flow of current through the auxiliary winding produces a magnetic flux that 
closes in a circle along the stator yoke. This flux is the source of the potential difference along the shaft. The frequencies of the shaft voltage and the current producing the flux are the same. The measurement results for various values of the voltage supplying the auxiliary winding are presented in Figure 20. They show that within the range of the measurements carried out, the tested electromagnetic circuit has an almost linear characteristic. Even a slight forcing of a circular flux results in the induction of the shaft voltage.

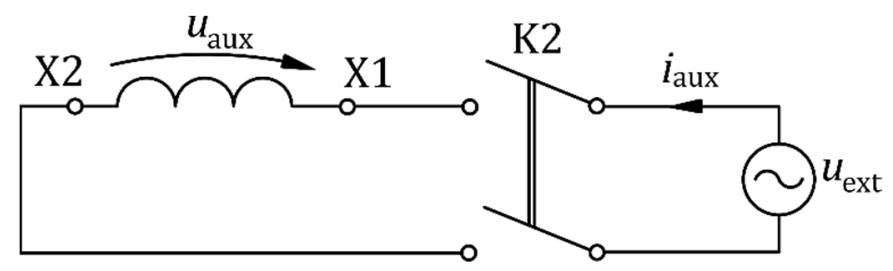

Figure 18. Schematic diagram of the auxiliary winding power supply from an external AC voltage source.

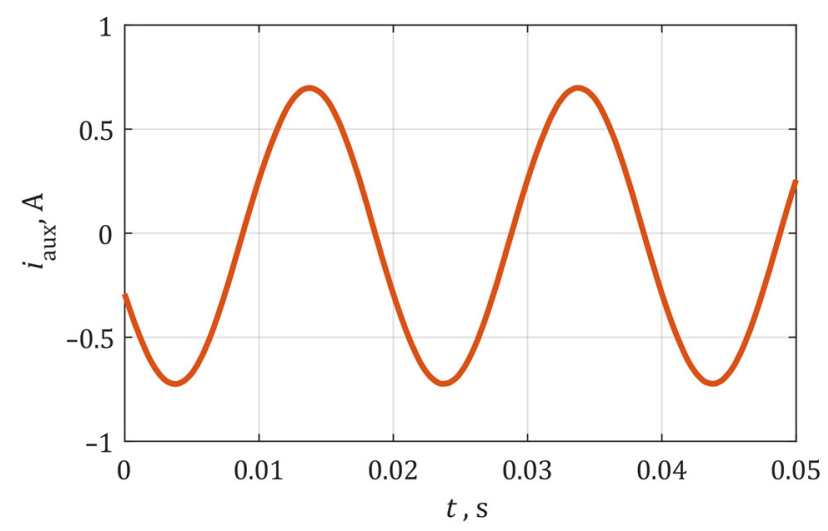

(a)

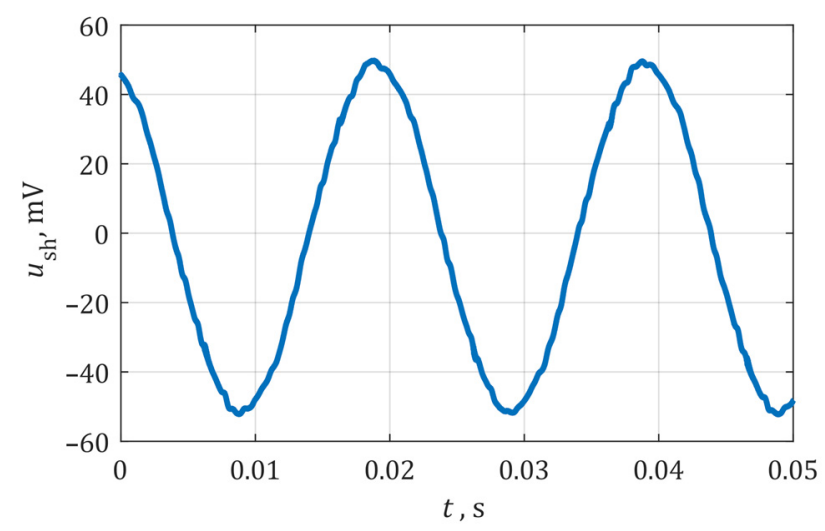

(b)

Figure 19. Current flowing in the auxiliary winding $i_{\text {aux }}(\mathbf{a})$ and the shaft voltage $u_{\mathrm{sh}}(\mathbf{b})$ in the case of a stopped rotor $(n=0)$.

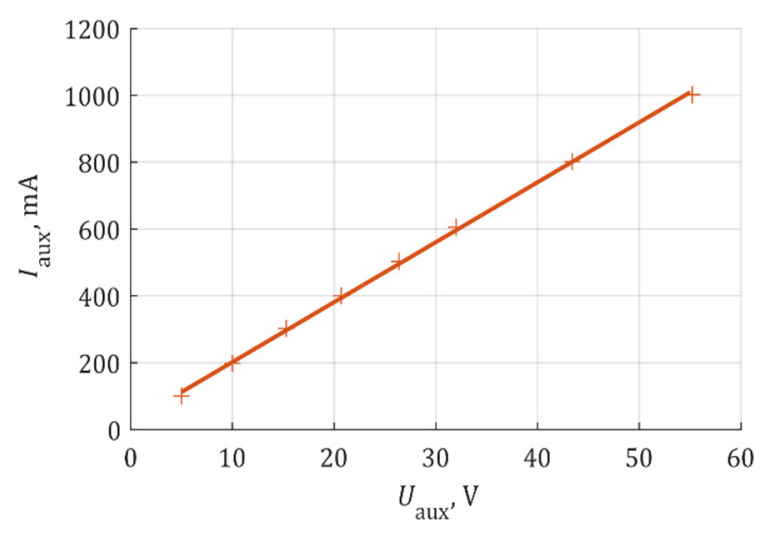

(a)

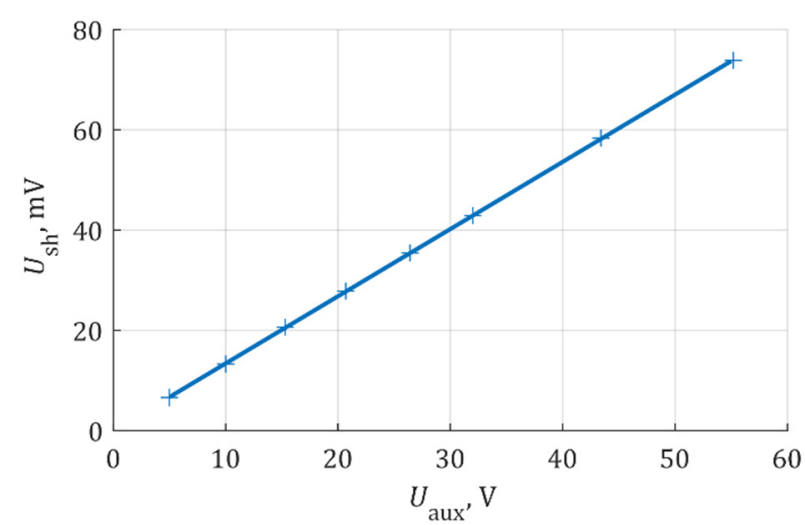

(b)

Figure 20. Auxiliary winding current (a) and shaft voltage (b) characteristics.

In the second part of research, the rotor of the tested permanent magnet machine was driven by an auxiliary machine to the synchronous speed $n=1500 \mathrm{rpm}$. The auxiliary winding was supplied from an adjustable alternating voltage source with a frequency of $f=50 \mathrm{~Hz}$, and then the shaft voltage waveforms were measured. The measurement results are presented in Figure 21. 


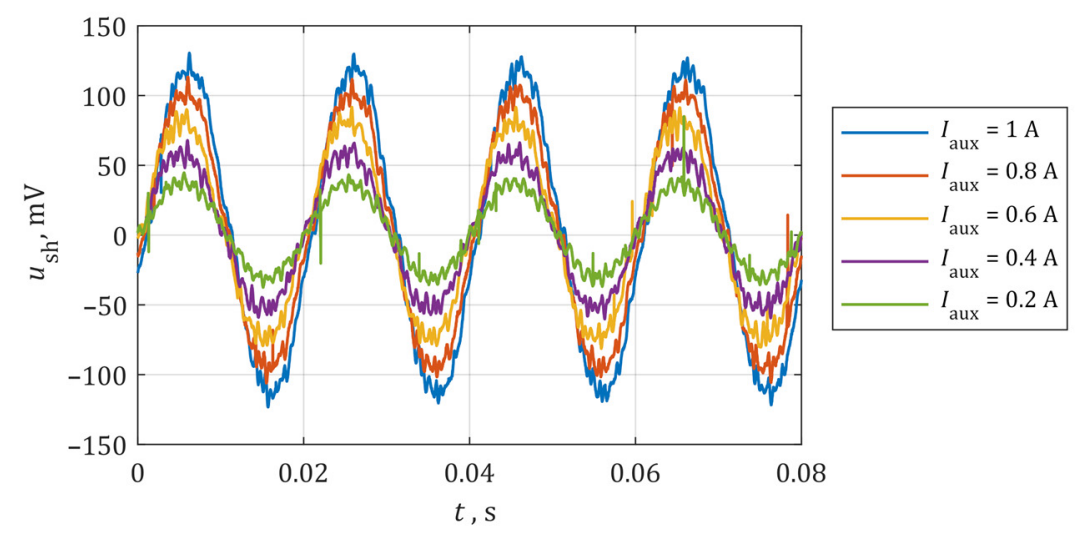

Figure 21. Voltage waveforms between the shaft ends at synchronous speed for different values of the current flowing in the auxiliary winding $I_{\mathrm{aux}}$.

On the basis of the obtained measurement results, it appears that the circular flux closing in the stator yoke is a direct source of voltage along the shaft of the machine. The frequency of this voltage depends on the frequency of the circular flux changes, and its value is proportional to the amplitude of the flux forced by the current flowing in the auxiliary winding. Work at no-load with random rotational speed differs from the working conditions in the steady state with the main flux that varies over time. This flux rotates synchronously in the direction of rotation of the rotor and closes through the air gap, teeth, stator yoke and rotor. The value of the flux density in individual parts of the stator varies over time. In the analyzed case, the shaft voltage is induced by the resultant flux: coming from both the powered auxiliary winding and the circular flux resulting from the tolerance chain of the test object.

Subsequently, measurements were conducted in no-load condition of the machine during the operation of the generator. Here, the measurements were limited to no-load condition in order to become independent from the possible power or load unbalances. In such an operating condition, the flux in the magnetic circuit comes only from permanent magnets placed on the rotor. The tested synchronous machine was driven to a speed of $1500 \mathrm{rpm}$, and its three-phase stator winding was open. In this variant, the measurements of the shaft voltage between the shaft journals were carried out with the auxiliary winding open and closed. The waveforms and frequency spectra of the shaft voltage and induced voltage in the open auxiliary winding are presented in Figures 22 and 23. There is a clear analogy between the shaft voltage and the voltage in the auxiliary winding-it is shown by, e.g., identical frequencies of dominant harmonics $(50 \mathrm{~Hz})$. The components with frequencies equal to $900 \mathrm{~Hz}$ are caused by the number of slots in the machine stator winding.

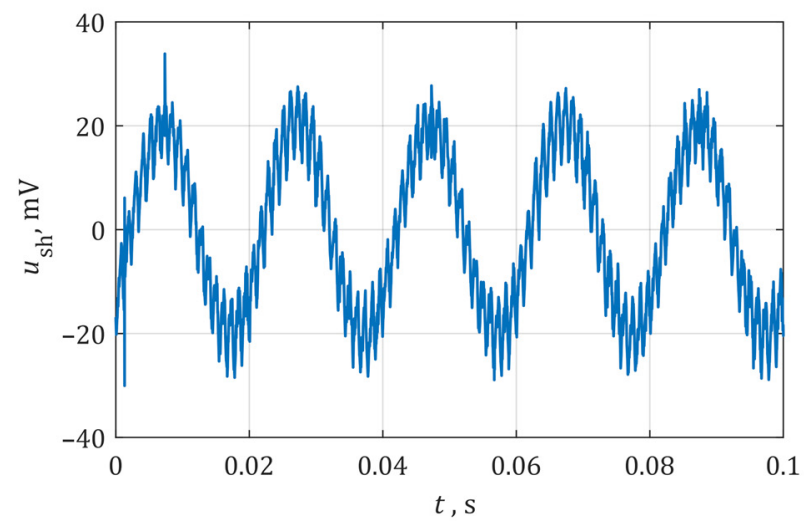

(a)

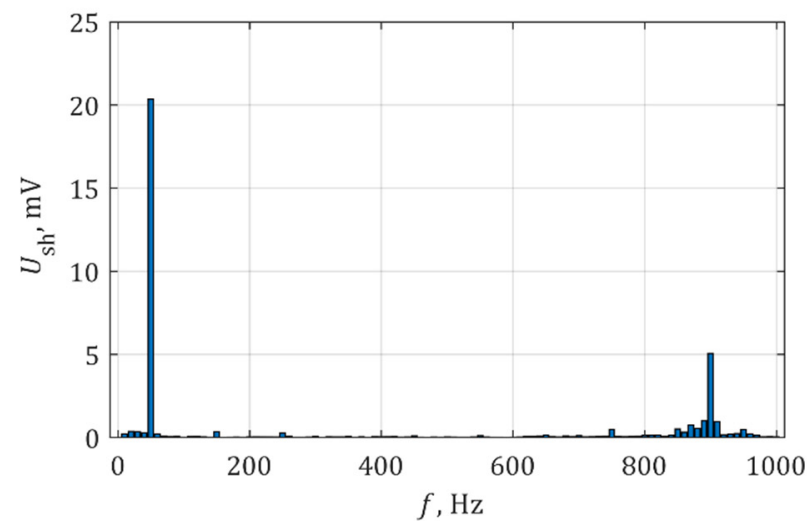

(b)

Figure 22. The waveform of the shaft voltage (a) and its amplitude spectrum (b) under no-load condition at the speed of $n=1500 \mathrm{rpm}$. 


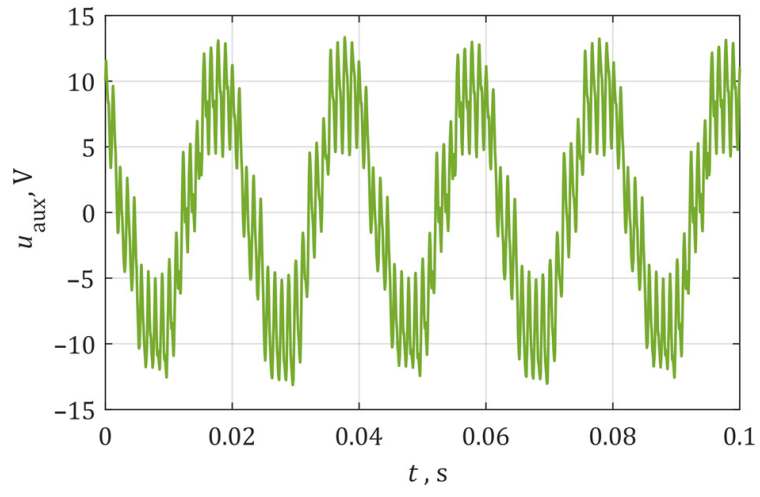

(a)

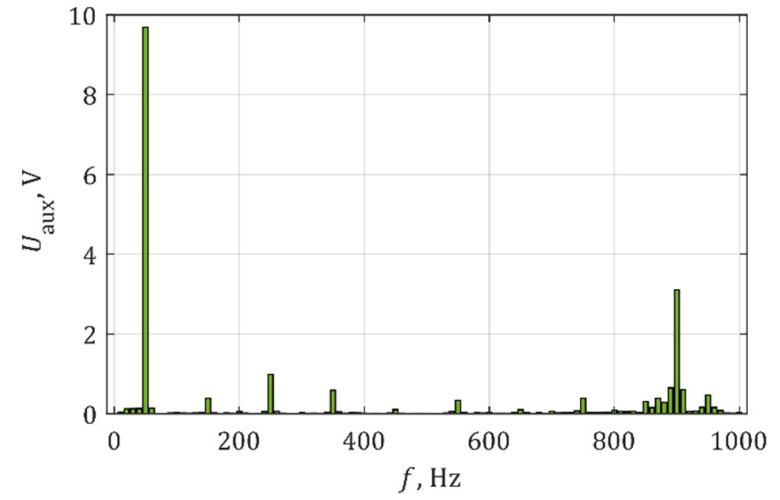

(b)

Figure 23. Waveform of the auxiliary voltage (a) and its amplitude spectrum (b) under no-load condition at the speed of $n=1500 \mathrm{rpm}$.

Short-circuiting of the auxiliary winding via K2 switch significantly affects the value of the shaft voltage. The shaft voltage waveforms for short-circuited and open-ended auxiliary winding are shown in Figure 24. The values of the shaft voltage for various rotational speeds of the generator are presented in Figure 25 and in a tabular form in Table 2. For each rotational speed of the generator running at idle speed, a significant reduction of the shaft voltage was observed after short-circuiting of the auxiliary winding. The current flowing through the shorted auxiliary winding for frequencies above $20 \mathrm{~Hz}$ practically does not change-it results from changes in the impedance of the auxiliary winding, the main part of which is the inductive reactance.

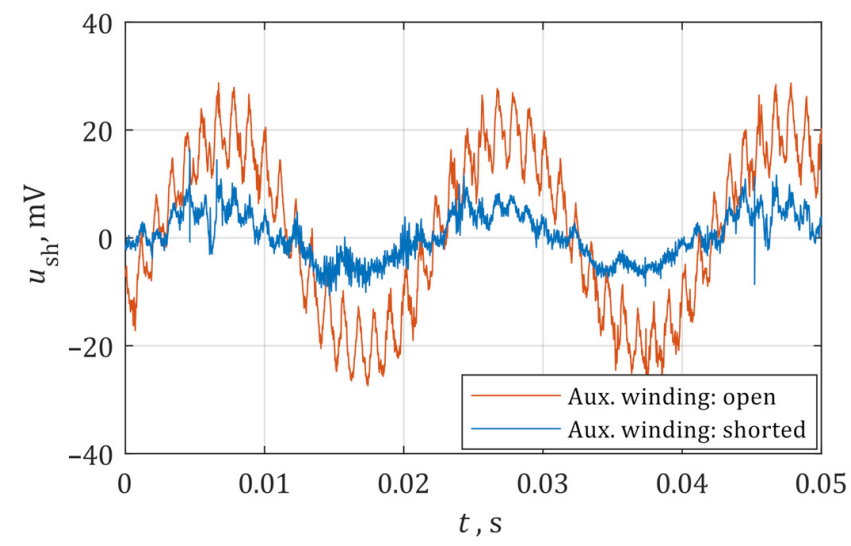

Figure 24. Shaft voltage waveforms with short-circuited and open auxiliary winding.

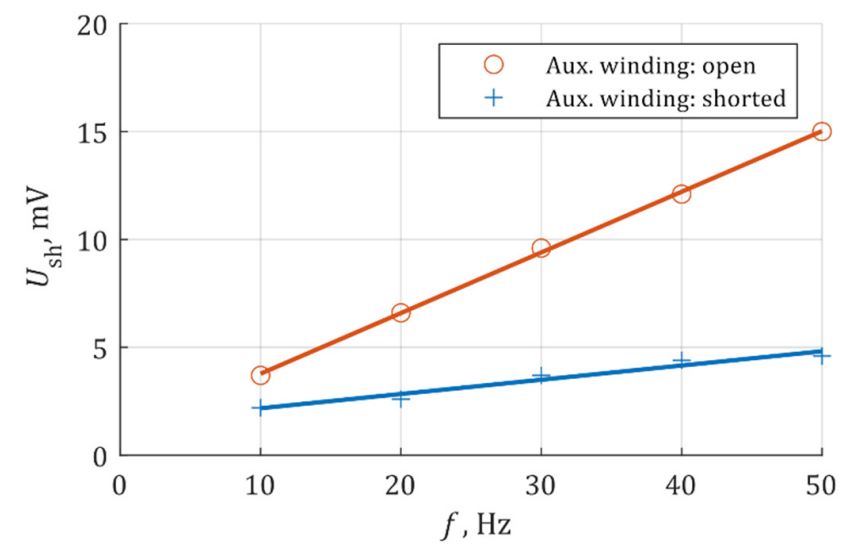

Figure 25. Characteristics of the shaft voltage with shorted and open auxiliary winding. 
Table 2. Summary of measurement results for no-load condition.

\begin{tabular}{cccccc}
\hline \multirow{2}{*}{ Rotation Speed $\boldsymbol{n}, \mathbf{r p m}$} & $\begin{array}{c}\text { Winding } \\
\text { Voltage } \boldsymbol{f}, \mathbf{H z}\end{array}$ & \multicolumn{2}{c}{$\begin{array}{c}\text { Open Auxiliary } \\
\text { Winding }\end{array}$} & \multicolumn{2}{c}{$\begin{array}{c}\text { Short-Circuited } \\
\text { Auxiliary Winding }\end{array}$} \\
\cline { 3 - 6 } & & $\boldsymbol{U}_{\mathbf{s h}}, \mathbf{m V}$ & $\boldsymbol{U}_{\mathbf{a u x}}, \mathbf{V}$ & $\boldsymbol{U}_{\mathbf{s h}}, \mathbf{m V}$ & $\boldsymbol{I}_{\mathbf{a u x}}, \mathbf{m A}$ \\
\hline 300 & 10 & 3.7 & 1.52 & 2.2 & 123 \\
600 & 20 & 6.6 & 2.93 & 2.6 & 133 \\
900 & 30 & 9.6 & 4.45 & 3.7 & 134 \\
1200 & 40 & 12.1 & 5.88 & 4.4 & 134 \\
1500 & 50 & 15.0 & 7.38 & 4.6 & 134 \\
\hline
\end{tabular}

In order to investigate the influence of the auxiliary winding on the induced voltage waveforms at the terminals of the main winding, measurements were carried out at the rated rotational speed at no-load conditions with the auxiliary winding short-circuited and open. Figure 26 shows the measured waveforms of phase voltages with the auxiliary winding shorted and open. In order to increase the clarity, these waveforms are presented for one stator phase. The presented waveforms show that the auxiliary winding shortcircuit practically does not affect the phase voltage waveforms and, consequently, does not affect the main flux of the machine either.

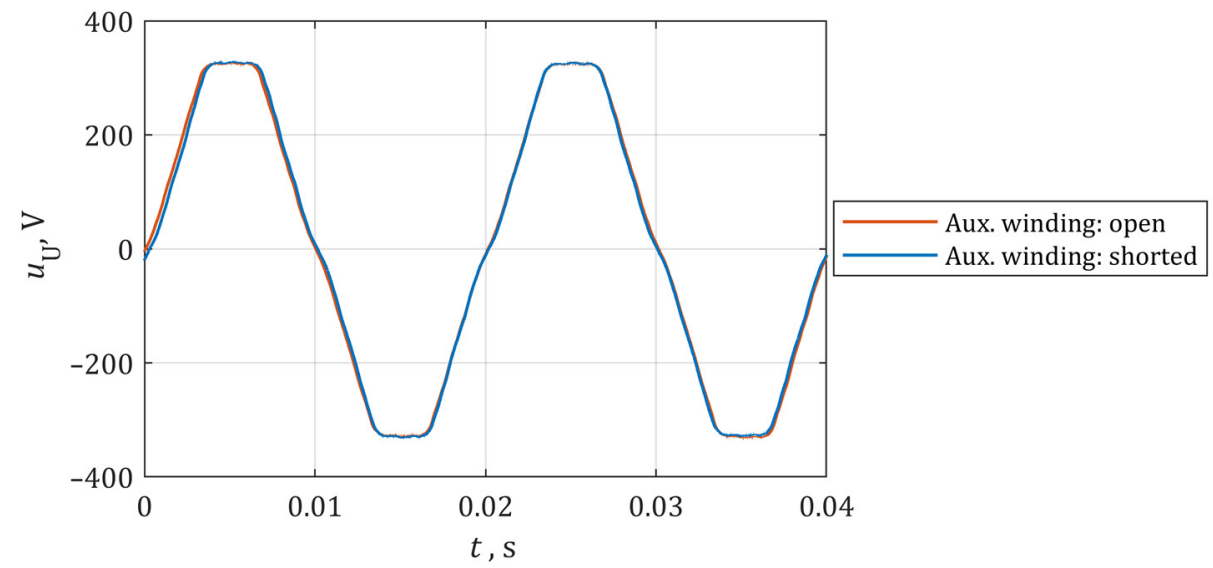

Figure 26. Waveforms of induced voltages in no-load condition of the main winding phase for open and shorted auxiliary winding $(n=1500 \mathrm{rpm})$.

The last stage of the tests was generator operation under load. The load of the synchronous machine with permanent magnets was obtained by connecting the generator to the grid. For this purpose, a regulated three-phase voltage source was used. After driving the generator to synchronous speed and synchronizing the generator and network voltages, the $\mathrm{K} 1$ contactor was closed, thus connecting the generator winding to the network. Due to the lack of the excitation winding of the synchronous machine with permanent magnets, the change of the machine loading conditions was carried out by simultaneously adjusting the torque on the machine shaft and the voltage in the grid. Measurements were carried out for operating conditions presented in the first column of Table 3.

The values of the shaft voltages and shaft currents for the tested operating conditions are compared in Table 3 . They show that the short-circuit of the auxiliary winding limits the values of shaft voltages and currents by more than 3 times, both at idle and under load. The short-circuit of the auxiliary winding does not affect the operating parameters of the machine, and in particular its efficiency, because the active power consumed in the short-circuited auxiliary winding does not exceed several hundred milliwatts. 
Table 3. Summary of measurement results for various operating states.

\begin{tabular}{|c|c|c|c|c|}
\hline & \multicolumn{2}{|c|}{ Shaft Voltage $U_{\mathrm{sh}}, \mathrm{mV}$} & \multicolumn{2}{|c|}{ Shaft Current $I_{\mathrm{sh}}, \mathrm{A}$} \\
\hline & $\begin{array}{l}\text { Auxiliary Winding } \\
\text { Open }\end{array}$ & $\begin{array}{l}\text { Short-Circuited Aux. } \\
\text { Winding }\end{array}$ & $\begin{array}{l}\text { Auxiliary Winding } \\
\text { Open }\end{array}$ & $\begin{array}{l}\text { Short-Circuited Aux. } \\
\text { Winding }\end{array}$ \\
\hline $\begin{array}{c}\text { No-load: } \\
f=50 \mathrm{~Hz} \\
\text { Load: }\end{array}$ & 15.0 & 4.6 & 2.20 & 0.65 \\
\hline $\begin{array}{c}f=50 \mathrm{~Hz}, P_{2}=3.1 \mathrm{~kW} \\
I=4.5 \mathrm{~A}, \cos \varphi=0.99 \\
\text { Load: }\end{array}$ & 16.7 & 5.5 & 1.86 & 0.52 \\
\hline $\begin{array}{c}f=50 \mathrm{~Hz}, P_{2}=2.3 \mathrm{~kW} \\
I=4.5 \mathrm{~A}, \cos \varphi=0.8\end{array}$ & 17.8 & 6.0 & 2.00 & 0.40 \\
\hline
\end{tabular}

\section{Conclusions}

The presented method of limiting shaft voltages in AC electric machines using an additional auxiliary winding in the stator is a new solution. The results of the measurements carried out with the prototype of a synchronous machine with permanent magnets confirm the beneficial effect of the use of the winding on the level of shaft voltage and shaft currents in an electrical machine. This method has a large application potential that can positively affect the reliability of drive systems with AC electric machines. The authors believe that the proposed method can be used in high-power drive systems supplied directly from mains voltage, also for economic reasons. The implementation of the described auxiliary winding involves, among others, the development of additional construction documentation and technological processes related to the winding and insulation of this winding. This solution also requires the use of an iron core with a modified shape.

Based on the measurements, the direct dependence of voltage induced between shaft ends on magnetic flux closing in the stator yoke has been shown. The voltage induced at the auxiliary winding terminals is directly proportional to the number of turns of the auxiliary winding. The voltage at the terminals of the open auxiliary winding obtained during the measurements proves the presence of a circular flux. Even though the research object was not intentionally asymmetrical (asymmetry related to its electromagnetic circuit), such asymmetry appeared as a result of manufacture of this model (total resultant material and dimensional tolerance chain). It is worth noting that in the case of small-dimension machines, it is not difficult to find small but significant deviations in execution. The asymmetry of the flux in the electromagnetic circuit in the case of the research object may be the result of the asymmetry of the air gap or the arrangement of magnets placed on the rotor, which was confirmed on the basis of the simulations performed (Figures 14 and 23).

When analyzing the presented results of a series of measurements, it should also be noted that the constructed model of the machine with permanent magnets was intended to confirm the validity of the idea of using the auxiliary winding. Its dimensions were limited to the small size of the frame. For this reason, the obtained shaft voltage values are clearly lower than the level assumed as dangerous for the technical condition of the bearings.

The constructed test stand will be used for further measurements, e.g., to determine the influence of the additional auxiliary winding in dynamic machine operating states. It is also planned to manufacture special shields and bearing assemblies that enable precise introduction of the variable thickness of the air gap between the stator and the rotor in a controlled manner.

Additionally, there are plans to develop a three-dimensional field-circuit model of the synchronous machine. Such tests will enable qualitative determination of the influence of the auxiliary winding on the induced voltage waveforms with the eccentric position of the rotor. In particular, there are plans to conduct tests for static eccentricity (the rotor axis of rotation is shifted in relation to the stator axis) and dynamic eccentricity (the rotor axis does not coincide with the axis of its rotation). It is also advisable to conduct research 
on the influence of various machine design solutions, such as changing the dimensions and shape of the stator slots, the skew of the permanent magnets on the waveforms of the machine shaft voltages.

Author Contributions: Conceptualization, S.B. and T.J.; methodology, S.B. and T.J.; measurements, S.B. and T.J.; writing-Review and editing, S.B. and T.J. All authors have read and agreed to the published version of the manuscript.

Funding: The research is co-financed under the Program of the Ministry of Science and Higher Education "Implementation Doctorate" (Poland).

Institutional Review Board Statement: Not applicable.

Informed Consent Statement: Not applicable.

Data Availability Statement: Not applicable.

Conflicts of Interest: The authors declare no conflict of interest.

\section{References}

1. Boldea, I. Electric Generators and Motors: An overview. Trans. Electr. Mach. Syst. 2017, 1, 3-14. [CrossRef]

2. Merizalde, Y.; Hernández-Callejo, L.; Duque-Perez, O. State of the Art and Trends in the Monitoring, Detection and Diagnosis of Failures in Electric Induction Motors. Energies 2017, 10, 1056. [CrossRef]

3. Pyrhonen, J. Design of Rotating Electrical Machines; Wiley: Chichester, West Sussex, UK; Hoboken, NJ, USA, 2008; ISBN 978-0-47069516-6.

4. Baranski, M.; Decner, A.; Polak, A. Selected Diagnostic Methods of Electrical Machines Operating in Industrial Conditions. IEEE Trans. Dielect. Electr. Insul. 2014, 21, 2047-2054. [CrossRef]

5. Cheng, M.; Sun, L.; Buja, G.; Song, L. Advanced Electrical Machines and Machine-Based Systems for Electric and Hybrid Vehicles. Energies 2015, 8, 9541-9564. [CrossRef]

6. Pielecha, I.; Cieślik, W.; Szałek, A. Operation of Electric Hybrid Drive Systems in Varied Driving Conditions. Maint. Reliab. 2018, 20, 16-23. [CrossRef]

7. Lei, G.; Zhu, J.; Guo, Y.; Liu, C.; Ma, B. A Review of Design Optimization Methods for Electrical Machines. Energies 2017, 10, 1962. [CrossRef]

8. Trigeassou, J.-C. (Ed.) Electrical Machines Diagnosis; ISTE: London, UK, 2011; ISBN 978-1-84821-263-3.

9. Sun, X.; Zhang, Y.; Lei, G.; Guo, Y.; Zhu, J. An Improved Deadbeat Predictive Stator Flux Control with Reduced-Order Disturbance Observer for In-Wheel PMSMs. IEEE/ASME Trans. Mechatron 2021, 1115-1125. [CrossRef]

10. Galea, M.; Giangrande, P.; Madonna, V.; Buticchi, G. Reliability-Oriented Design of Electrical Machines: The Design Process for Machines' Insulation Systems MUST Evolve. IEEE Ind. Electron. Mag. 2020, 14, 20-28. [CrossRef]

11. Imoru, O.; Jimoh, A.A.; Hamam, Y. Origin and Manifestation of Electrical Machine Faults-A Review. In Proceedings of the 2nd IEEE Conference on Power Engineering and Renewable Energy (ICPERE), Bali, Indonesia, 9-11 December 2014; IEEE: Bali, Indonesia, 2014; pp. 189-194.

12. Gritli, Y. Diagnosis and Fault Detection in Electrical Machines and Drives Based on Advanced Signal Processing Techniques. Ph.D. Thesis, Università di Bologna, Bologna, Italy, 2014.

13. Costello, M.J. Shaft Voltages and Rotating Machinery. IEEE Trans. Ind. Appl. 1993, 29, 419-426. [CrossRef]

14. Sun, X.; Jin, Z.; Chen, L.; Yang, Z. Disturbance Rejection Based on Iterative Learning Control with Extended State Observer for a Four-Degree-of-Freedom Hybrid Magnetic Bearing System. Mech. Syst. Signal Process. 2021, 153, 107465. [CrossRef]

15. Sun, X.; Jin, Z.; Cai, Y.; Yang, Z.; Chen, L. Grey Wolf Optimization Algorithm Based State Feedback Control for a Bearingless Permanent Magnet Synchronous Machine. IEEE Trans. Power Electron. 2020, 35, 13631-13640. [CrossRef]

16. SKF. SKF Bearing Maintenance Handbook; SKF: Göteborg, Sweden, 2011; ISBN 978-91-978966-4-1.

17. Rolling Bearing Damage. Recognition of Damage and Bearing Inspection; Schaeffler Group Industrial: Schweinfurt, Germany, 2001.

18. Timken Bearing Damage Analysis with Lubrication Reference Guide; The Timken Company: North Canton, OH, USA, 2015.

19. Bearing Failure: Causes and Cures; Barden Precision Bearings: Danbury, Connecticut, 1998.

20. Bonnett, A.H. Cause and Analysis of Bearing Failures in Electrical Motors. In Proceedings of the [1992] Record of Conference Papers Industry Applications Society 39th Annual Petroleum and Chemical Industry Conference; IEEE: San Antonio, TX, USA, 1992; pp. 87-95.

21. Upadhyay, R.K.; Kumaraswamidhas, L.A.; Azam, M.S. Rolling Element Bearing Failure Analysis: A Case Study. Case Studies in Engineering Failure Analysis. Elsevier 2013, 1, 15-17. [CrossRef]

22. Alger, P.L.; Samson, H.W. Shaft Currents in Electric Machines. Trans. Am. Inst. Electr. Eng. 1924, XLIII, 235-245. [CrossRef]

23. Ong, R.; Dymond, J.H.; Findlay, R.D.; Szabados, B. Shaft Current in AC Induction Machine. An Online Monitoring System and Prediction Rules. IEEE Trans. Ind. Appl. 2001, 37, 1189-1196. [CrossRef] 
24. Plazenet, T.; Boileau, T.; Caironi, C.; Nahid-Mobarakeh, B. An Overview of Shaft Voltages and Bearing Currents in Rotating Machines. In Proceedings of the 2016 IEEE Industry Applications Society Annual Meeting, Portland, OR, USA, 2-6 October 2016; IEEE: Portland, OR, USA, 2016; pp. 1-8.

25. Chapter 2 Shaft voltages and their origin in rotating machines and flow of electric current through bearings. Tribol. Interface Eng. Ser. 2006, 49, 15-23.

26. Motor Shaft Voltages and Bearing Currents under PWM Inverter Operation, Gambica/BEAMA Technical Guide, 3rd ed.; The Gambica Association Ltd.: London, UK, 2016.

27. IEEE P1812/D2, January 2013: IEEE Draft Trial-Use Guide for Testing Permanent Magnet Machines; IEEE: New York, NY, USA, 2013; ISBN 978-0-7381-8289-6.

28. Bobon, A.; Zientek, P.; Niestroj, R.; Pasko, M.; Kwak, J. The Computational and Measurement Methods of Research on Factors Affecting the Flow of Bearing Currents in High Power Induction Motors. In Proceedings of the 2016 13th Selected Issues of Electrical Engineering and Electronics (WZEE), Rzeszów, Poland, 4-8 May 2016; IEEE: Rzeszów, Poland, 2016; pp. 1-6.

29. Stone, G.; Lloyd, B.; Sasic, M. Monitoring of Shaft Voltages and Grounding Currents in Rotating Machines. In Proceedings of the 2014 17th International Conference on Electrical Machines and Systems (ICEMS), Hangzhou, China, 22-25 October 2014; IEEE: Hangzhou, China, 2014; pp. 3361-3364.

30. INSOCOAT Electrically Insulated Rolling Bearings—A Solution for Increased Reliability and Machine Uptime; SKF: Göteborg, Sweden, 2016.

31. Sohre, J.S.; Nippes, P.L. Electromagnetic Shaft Currents and Demagnetization on Rotors of Turbines and Compressors. In Proceedings of the 7th Turbomachinery Symposium, College Station, TX, USA, 6-8 December 1978. [CrossRef]

32. Jarek, T.; Berhausen, S. Analysis of the impact of an auxiliary winding of a permanent magnet synchronous machine on the generation of shaft voltages. In Proceedings of the 2019 15th Selected Issues of Electrical Engineering and Electronics, Zakopane, Poland, 8-10 December 2019; IEEE: Zakopane, Poland, 2019; pp. 1-4. 